INVESTIGACIÓN

Recibido: 17/02/2021 --- Aceptado: 25/03/2021 --- Publicado: 10/05/2021

\title{
LOS MEDIOS DE COMUNICACIÓN ESPAÑOLES EN TIEMPOS DE PANDEMIA: GENERACIÓN DE NOTICIAS EN REDES SOCIALES DURANTE LA COVID-19
}

\section{The spanish media in times of pandemic: news generation on social media during COVID-19}

Sandro Arrufat Martín¹. Universidad Rey Juan Carlos. España. sandro.arrufat@urjc.es

\section{Cómo citar el artículo:}

Arrufat Martín, S. (2021). Los medios de comunicación españoles en tiempos de pandemia: generación de noticias en redes sociales durante la COVID-19. Vivat Academia. Revista de Comunicación, 154, 107-122. http://doi.org/10.15178/va.2021.154.e1309 http://www.vivatacademia.net/index.php/vivat/article/view/1309

\section{RESUMEN}

La presente investigación presenta un estudio cuantitativo de la información difundida por los principales medios de comunicación españoles en sus perfiles de redes sociales durante la etapa de inicio de la pandemia en España hasta la conclusión del primer Estado de alarma decretado por el Gobierno español, analizando sus principales ratios. En este sentido, los resultados expuestos evidencian el grado de interés por parte de los ciudadanos en la información relativa a la COVID-19 durante el marco temporal establecido y en qué canales sociales han tenido mayor interacción y aceptación estos mensajes, siendo Instagram la red social con mejor aceptación para mensajes de carácter social. Asimismo, la investigación ha posibilitado obtener datos precisos sobre qué redes sociales responden mejor dependiendo el tipo de mensajes y contenidos difundidos. Además, el diseño metodológico de la investigación ha propiciado obtener resultados acerca de otros temas sociales de interés y actualidad que no guardan relación con la pandemia y que los medios de comunicación también generaban en su discurso durante los meses establecidos.

\footnotetext{
${ }^{1}$ Sandro Arrufat Martín: Profesor Asociado en la Universidad Rey Juan Carlos y docente e investigador en EAE Business School. Doctor en Ciencias de la Comunicación por la Universidad Rey Juan Carlos.
} 
Arrufat Martín, S.

Los medios de comunicación españoles en tiempos de pandemia: generación de noticias en redes sociales durante la COVID-19

PALABRAS CLAVE: COVID-19 - Pandemia - Virus - Redes sociales - Medios de comunicación - Noticias - Actualidad - Debate social - Información.

\begin{abstract}
This research presents a quantitative study on the information spreaded by the main Spanish media in their social network profiles during the onset stage of the pandemic in Spain until the conclusion of the first State of Alarm decreed by the Spanish Government. In this regard, the results presented show both, the degree of interest by citizens in the information related to COVID-19 during the established time frame and also in which social channels these messages have had greater interaction and acceptance. Likewise, the research has allowed to obtain precise data on which social networks respond best depending on the type of messages and content spreaded. In addition, the research methodological design has led to obtaining results on other social topics of interest and current affairs that are not related to the pandemic and that media also generated in their discourse during the established months for the analysis.
\end{abstract}

KEYWORDS: COVID-19 - Pandemic - Virus - Social networks - Media - News Present - Social debate - Information.

\title{
OS MEIOS DE COMUNICAÇÃO ESPANHÓIS EM TEMPOS DE PANDEMIA: GERAÇÃO DE NOTÍCIAS EM REDES SOCIAIS DURANTE O COVID-19
}

\section{RESUMO}

A presente pesquisa apresenta um estudo quantitativo da informação difundida pelos principais meios de comunicação espanhóis nos seus perfis das redes sociais durante a etapa do início da pandemia na Espanha até a conclusão do primeiro estado de alarme decretado pelo governo espanhol, analisando seus principais índices. Neste sentido os resultados expostos evidenciam o grau de interesse pelos cidadãos na informação relativa ao COVID-19 durante o marco temporal estabelecido e em que canais sociais tem maior interação e aceitação destas mensagens, sendo Instagram a rede social com melhor aceitação para mensagens de caráter social. Além disso, a pesquisa tem possibilitado obter dados precisos sobre que redes sociais respondem melhor dependendo do tipo de mensagem e os conteúdos difundidos. Por outro lado, a estratégia metodológica da pesquisa propicia obter resultados sobre outros temas sociais de interesse e sobre a atualidade que não possuem relação com a pandemia e que também eram gerados no seu discurso durante os meses estipulados.

PALAVRAS CHAVE: COVID-19 - Pandemia - Vírus - Redes sociais - Meios de comunicação - Notícias - Atualidade - Debate social - Informação. 
Arrufat Martín, S.

Los medios de comunicación españoles en tiempos de pandemia: generación de noticias en redes sociales durante la COVID-19

\section{INTRODUCCIÓN}

La preocupación extraordinaria generada en la sociedad debido a la COVID-19 se ve reflejada en el consumo de información de los públicos en los medios de comunicación y sus respectivos canales de difusión. Sin duda, ante una situación tan crítica y de tal calado como la que se está viviendo a nivel global, la información y los medios de comunicación se convierten en recurso esencial para reducir la incertidumbre ante el riesgo y facilitar la adaptación de nuestra conducta al nuevo escenario imprevisto.

La Organización Mundial de la Salud declaró la emergencia de salud pública de interés internacional debida a la COVID-19 en enero de 2020. Sin embargo, no fue hasta el 14 de marzo, cuando la OMS declaró la pandemia mundial debido a la gravedad y virulencia del virus. Como consecuencia, los países fueron tomando medidas de contención del virus y España, entre otros países, declaró el Estado de alarma a través de la publicación del Real Decreto 463/2020, de 14 de marzo (España, 2020), que obligaba al confinamiento total de la población durante un período inicial de 15 días, viéndose este prorrogado en varias ocasiones.

Ya Lubens (2015) planteó hace unos años el papel determinante que periodistas y profesionales de la salud desarrollan durante épocas de enfermedades, desempeñando ambas profesiones funciones claves con respecto a la percepción de la población, el flujo de información y la toma de decisiones. Podemos encontrar antecedentes próximos, aunque no en tal magnitud, respecto a la epidemia del Ébola en 2014. Y es en momento de alarma cuando los medios de comunicación adquieren un mayor nivel de poder y de importancia (Masip et ál., 2020). En tales circunstancias la ciudadanía exige y necesita más información, e información de calidad (Seeger et ál., 2003).

Un fenómeno de tan excepcionalidad, magnitud y relevancia social como es la pandemia del coronavirus, ha propiciado numerosa producción científica sobre este asunto, también en el ámbito de las ciencias de la comunicación. A modo de ejemplo, podemos mencionar estudios y análisis sobre la difusión de información en redes sociales (Ferrara, 2020), investigaciones relativas a las imágenes falsas difundidas sobre la pandemia (Andreu-Sñanchez et ál., 2020) y sobre el consumo informativo y cobertura mediática durante el confinamiento, entre otros (Masip et ál., 2020). También se han planteado análisis sobre la comunicación de las instituciones (Costa-Sánchez y LópezGarcía, 2020), o estudios comparativos entre los medios digitales y la prensa en papel (Lázaro y Herrera, 2020).

En consecuencia y en línea con la investigación comunicativa, la mayoría de propuestas intentan aproximarse al complejo proceso de influencia social de los medios (Wolf, 2011:9) como fuente de generación de opinión pública y creación de la imagen social de la pandemia. Sin embargo, y en relación a las ideas expuestas por Renn (1991) y Slovic (1987) en crisis sanitarias los ciudadanos tienden a confiar en menor medida en las instituciones, entre ellas los medios de comunicación. 
El ecosistema informativo ha variado notablemente hasta llegar al punto que "los hábitos de uso van más rápido que los agentes productores" (Costa-Sánchez, RodríguezVázquez y López-García, 2015:288), lo que ha propiciado un cambio en el paradigma del consumo de información ya no solo presente en los medios tradicionales, sino también en la red. El empleo de las nuevas tecnologías y de las redes sociales, en particular, ha propiciado un nuevo espacio de interacción social donde confluyen medios de comunicación, empresas, instituciones y personas. Los medios de comunicación han tenido que adaptar sus formas y canales de difusión de la información (Baraybar, Arrufat y Rubira, 2020:4), sin embargo, y pese al crecimiento experimentado por las redes sociales como forma de acceso a las noticias durante los últimos años (Newman et al., 2019), "los datos demuestran que no logran desbancar, durante esta crisis sanitaria, a los medios tradicionales como fuente prioritaria de información para los ciudadanos"

Casero-Ripollés, 2020:11).

Según un estudio de Larson (2020) a principios de abril de 2020, 113 millones de autores únicos habían compartido en Twitter mensajes sobre la COVID-19. En este sentido, el poder de la información asociada al virus ha inundado las redes sociales, fruto de la difusión e intercambio rápido de información por parte de los medios de comunicación en sus perfiles sociales (Aleixandre-Benavent et ál., 2020). En la actualidad, el espacio para el debate y la formulación de la opinión pública se ha extendido a las redes sociales (Papacharissi, 2010), incorporándose a la esfera pública preexistente (Guallar et al. 2016:359) y construyendo un sistema híbrido de comunicación en el que confluyen medios tradicionales y plataformas digitales (Chadwick, 2013). Aunque bien es cierto que hay que tener presente la sensación de saturación informativa que pueden existir en los públicos y que ya ha sido constatada en otras crisis (Abraham, 2005).

Los estudios que analizan el comportamiento y difusión de la información en redes sociales evidencian indicadores y ratios que aportan valiosa información cuantitativa y cualitativa a la hora poder analizar el llamado "análisis del sentimiento" en una comunidad (Yu; Duan; Cao, 2013; Ceron et al., 2014). Por tanto, este artículo intenta aportar datos cuantitativos que refuercen las tesis expuestas sobre el consumo de información y generación de interés durante el marco temporal establecido y con la temática relativa a la COVID-19. Asimismo, ahondamos sobre otras temáticas que han suscitado interés en el espacio de interacción social y esfera pública durante el confinamiento y que no guardan relación con el virus.

\section{OBJETIVOS}

La presente investigación tiene como principal objetivo el identificar el flujo de noticias referentes a la COVID-19 por parte de los medios de comunicación españoles más relevantes en sus respectivos perfiles sociales. En un primer lugar, la investigación intenta recoger los datos más destacados en las métricas de cada perfil social con el propósito de obtener información cuantitativa que indique qué medios y en qué canales han tenido un mejor rendimiento. Además, la investigación pretende 
Arrufat Martín, S.

Los medios de comunicación españoles en tiempos de pandemia: generación de noticias en redes sociales durante la COVID-19

determinar aquellos contenidos con mayor aceptación en cada una de las redes sociales por parte de los usuarios.

En segundo lugar, la investigación aportará los datos necesarios para interpretar qué tipo de contenidos informativos no relacionados con la temática del coronavirus suscitaron el interés del público durante el marco temporal establecido. Este punto aportará a la investigación los datos necesarios para comprender e interpretar la evolución sobre el interés informativo por parte de los usuarios en redes sociales sobre la COVID-19.

\section{METODOLOGÍA}

Como bien se expuso anteriormente, la investigación tiene dos puntos bien diferenciados. Por una parte, encontramos los datos de carácter cuantitativo que la investigación ha proporcionado sobre las métricas y contenidos, en relación al coronavirus, que han generado un mayor interés en los públicos y en los canales sociales de los medios de comunicación seleccionados. Y por otro, los datos relacionados con otro tipo de temáticas de carácter social que, informativamente, los usuarios demandaron en redes durante el periodo establecido.

El marco temporal de la investigación comprende desde el 1 de marzo hasta el 21 de junio de 2020. De esta manera se recogen los días previos a la proclamación del estado de alarma en España, con el fin de poder observar el crecimiento de la demanda de información sobre el objeto de estudio, y termina el día en que el gobierno español permitió la movilidad entre provincias y, en consecuencia, la expiración del decreto de emergencia. Para ello se han diferenciado las dos fases detalladas anteriormente, la primera desde el 1 de marzo al 31 de mayo, al detectar un periodo clave en la demanda de información sobre la COVID-19, y una segunda hasta el final del análisis donde la demanda de información sobre la pandemia comenzó a decrecer.

Para poder obtener los resultados de la investigación, se realizó, durante la fase exploratoria, un estudio técnico de las herramientas sociales y especializadas de obtención de métricas y análisis cuantitativos del comportamiento de las principales redes sociales. Para este estudio, se decidió emplear la aplicación de Data Analytics y Content Analytics de la empresa Welovroi. Es una aplicación que ofrece datos de carácter cuantitativo para analizar los principales ratios y el comportamiento de cada perfil en redes sociales gracias a sus dos componente de análisis. El primer componente (Data Analytics) permitió la comparativa de los distintos perfiles examinados según las métricas (KPIs) elegidas dentro del rango temporal programado y su representación gráfica. La segunda (Content Analytics) facilitó la posibilidad de analizar y filtrar los distintos contenidos que tuviesen relación o no con la temática del COVID-19. Una vez extraído los datos del análisis por la herramienta, se trataron en conjunto para poder seleccionar los resultados más relevantes para el estudio y así poder realizar las diferentes comparativas. 
Arrufat Martín, S.

Los medios de comunicación españoles en tiempos de pandemia: generación de noticias en redes sociales durante la COVID-19

Para poder obtener la información segmentada por temática se procedió a establecer palabras claves que cribaran las informaciones. Para diferenciar la temática de la COVID-19 con otras, se segmentó en la aplicación con las siguientes palabras claves: coronavirus, confinamiento, virus, pandemia, cacerolada, cuarentena, contagios, epidemia, alarma, mascarillas, desinfectante y muertos. Por su parte, la muestra de medios de comunicación atendió a los diferentes soportes del mercado español: prensa, la radio y televisión. A su vez, se seleccionaron a los medios siguiendo el criterio de difusión y del número de lectores, oyentes y espectadores según el Estudio General de Medios (EGM, 2020), cuyos datos son referencia entre los propios medios. Por tanto, se analizó la difusión de las cuentas oficiales en las redes sociales de los periódicos El País, El Mundo y ABC; de las emisoras de radio Cadena Ser, Cope y Onda Cero; por último, de las emisoras de televisión TVE, Antena 3, Telecinco y La Sexta. En lo referente a la segmentación de las redes sociales elegidas, atiende a uso según el Estudio en Redes Sociales 2020 del International Advertising Bureau Spain (IAB Spain, 2020), siendo estudiadas Facebook, Twitter, Instagram y YouTube.

\section{RESULTADOS}

\subsection{Datos totales y rendimiento de los medios de comunicación en redes sociales sobre la COVID-19.}

El total de publicaciones durante el período de la investigación sobre la COVID-19 por parte de los medios de comunicación seleccionados en redes sociales fue de 69.804 publicaciones, observándose una tendencia bajista a lo largo del tiempo y centrando el pico de publicaciones en el período comprendido en el primer Estado de alarma decretado por el Gobierno de España y, concretamente, el 12-13 de marzo de 2020. La tensión informativa de los medios de comunicación se centró durante las tres últimas semanas de este mes.

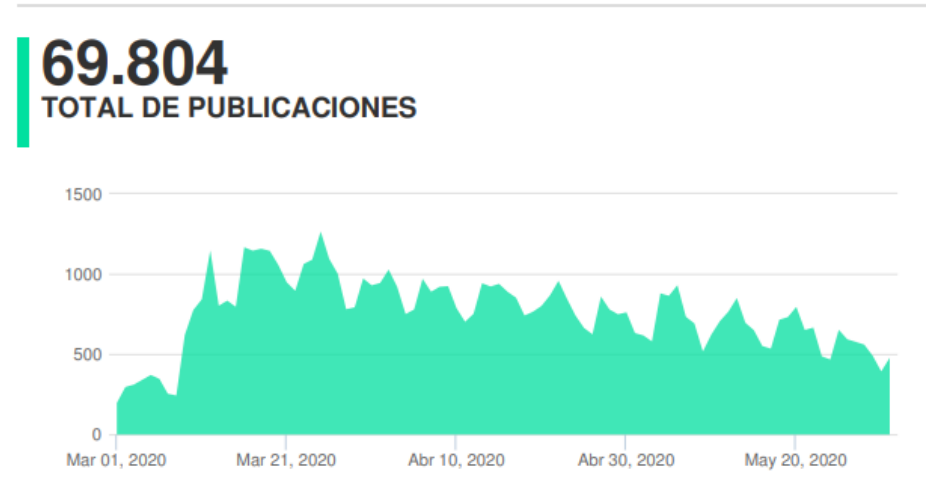

Figura 1. Total de publicaciones en redes sociales Fuente: Elaboración propia a partir de Welovroi

Del mismo modo, la COVID-19 ha sido el tema central durante estos tres meses y así se evidencia en la tasa de interacción en las redes sociales analizadas por parte de los usuarios. Durante el marco temporal establecido, analizamos un total de 50.473.226 
de interacciones, viéndose estas muy reducidas durante el mes de mayo en comparación con marzo. El nivel de interacción de los usuarios comenzó a descender a partir del 11 de abril. La investigación evidencia que la tasa de interacción decrece a mayor ritmo que la tasa de publicación durante los meses de abril y mayo. Los medios de comunicación continuaban acaparando sus informaciones con temáticas relacionadas con el virus, pero el interés del público ha ido disminuyendo después del período estival de semana santa, pero manteniéndose constante durante el mes de mayo. En este sentido, nos encontramos una media de interacciones general de 723,17 durante todo el período, concentrando una media de interacciones en marzo de 830,37, en abril de $711,77(-14,72 \%)$ y en mayo de $605,31(-15,27 \%)$.

\subsection{3 .226 \\ TOTAL DE INTERACCIONES}

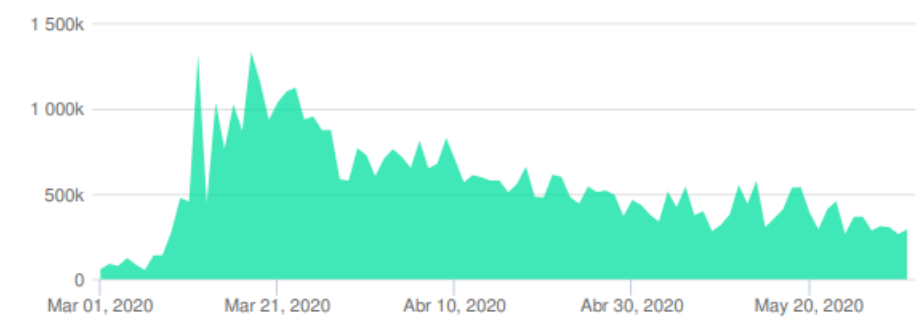

Figura 2:.Total de interacciones en redes sociales Fuente: Elaboración propia a partir de Welovro

La prensa (36,7M de interacciones) ha sido el sector de los medios de comunicación que mejor aceptación y tasa de interacción ha tenido en redes sociales, frente a las televisiones (7,98M.) y las radios (5,77M).

Concretamente, el diario El País ha sido el medio con mejor tasa de interacción en el marco temporal y temática del presente estudio. De hecho, se ve reforzada la tesis de que El País es el medio que más ha acaparado la atención de los usuarios de redes sociales ya que su perfil de Facebook y Twitter se sitúa dentro del TOP5 por delante de otros medios. Entre sus dos cuentas congregan una tasa de más de 13 millones de interacciones en los tres meses del estudio. Del mismo modo, destaca que el mayor porcentaje de interacción de todos los medios de comunicación se concentra en Facebook. Telecinco es el medio televisivo que mayor interacción suscita en su sector, seguido de la Cadena Ser en el sector radiofónico.

Los resultados de la investigación demuestran que la red social que congrega una mayor tasa de publicaciones es Twitter seguida de Facebook. En este sentido, se evidencia que no una mayor tasa de publicación conlleva una mayor tasa de interacción. De hecho, observamos como la red social Instagram no se encuentra en la tabla TOP10 de publicaciones y sí en la de interacciones. De estos resultados podemos extraer la conclusión de que medios como El País, ABC y la Cadena SER invierten más esfuerzos 
Arrufat Martín, S.

Los medios de comunicación españoles en tiempos de pandemia: generación de noticias en redes sociales durante la COVID-19

en publicar en perfiles de redes sociales contrarios a lo que marca su tasa de interacciones.

Por tanto, la red social que ha congregado la mayor tasa de publicación durante el marco temporal ha sido Twitter $(48,9 \%)$, seguido por Facebook $(45,1 \%)$, Instagram $(4,7 \%)$ y YouTube $(1,4 \%)$. En cambio, la red social que ha tenido una mayor tasa de interacciones ha sido Facebook (70,2\%), seguido de Twitter (13,9\%), Instagram $(11,6 \%)$ y YouTube $(4,3 \%)$.

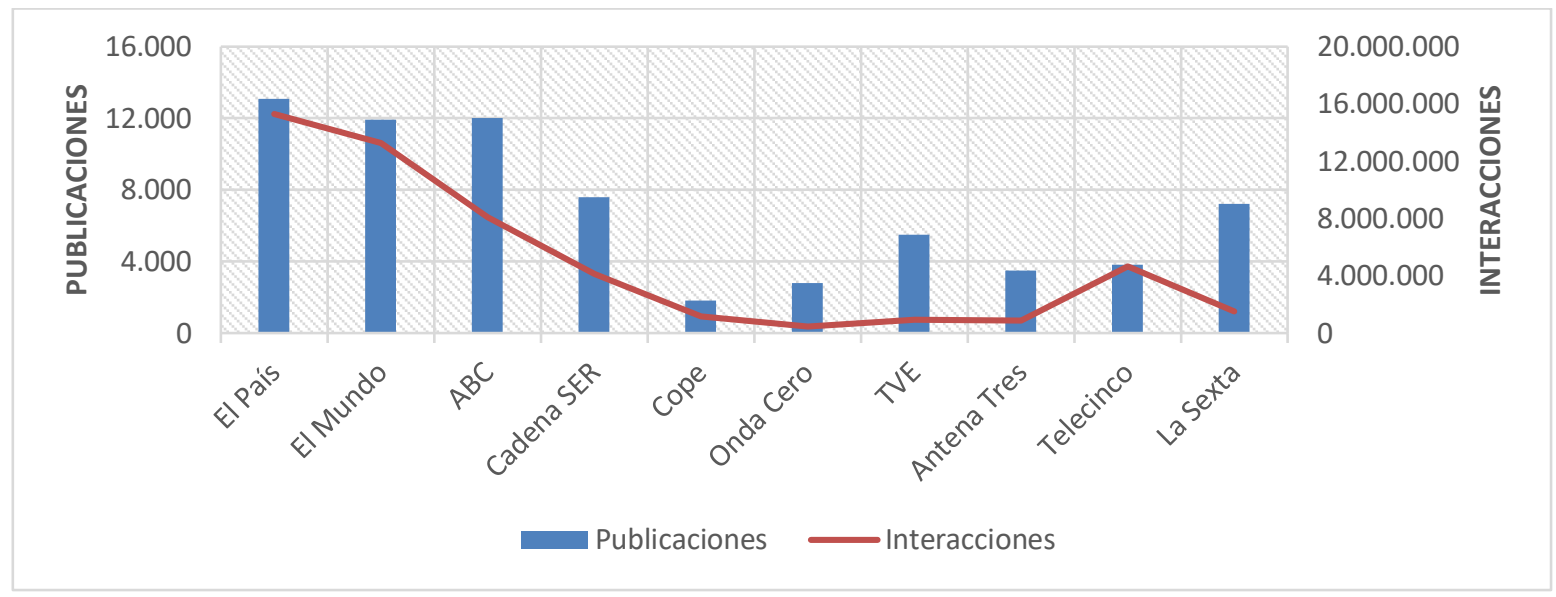

Figura 3. Relación directa entre publicaciones e interacciones por medio Fuente: Elaboración propia a partir de Welovroi

No siempre existe un equilibrio entre publicaciones e interacciones. El usuario de redes sociales premia más un contenido de calidad que la periodicidad de los posts. En este caso en concreto observamos claras diferencias y desigualdades entre la tasa de publicación e interacción. Hay muchos medios de comunicación que han dedicado recursos humanos y materiales para mantener actualizados los perfiles de redes sociales con noticias relativas a la COVID-19 por encima de la media y aumentando sus propios patrones de publicaciones regulares sin obtener ningún beneficio a cambio por parte de la audiencia.

En la gráfica se evidencia cómo el tráfico de publicaciones e interacciones se concentra en las cuentas de los tres medios de prensa de tirada nacional analizados (El País, El Mundo y $\mathrm{ABC}$ ), existiendo poco equilibrio entre su tasa de publicación e interacción. En cuanto a la primera, el porcentaje entre los tres medios es casi el mismo, mientras que los resultados varían si analizamos la tasa de interacción donde observamos que El País, aun sumando los mismos esfuerzos en publicaciones, se lleva la medalla de oro y el reconocimiento de la audiencia en sus perfiles de redes sociales.

\subsection{Contenido informativo con mayor interés relacionado con la COVID-19.}

Durante el marco temporal del estudio, los usuarios han interactuado acerca de la COVID-19 con multitud de etiquetas, siendo los hashtags que se presentan en la imagen 
Arrufat Martín, S.

Los medios de comunicación españoles en tiempos de pandemia: generación de noticias en redes sociales durante la COVID-19

los que más interacciones han congregado. En este sentido, \#coronavirus ha sido la etiqueta más empleada durante los tres meses del estudio con más de 3,97 millones de interacciones. Completan las tres primeras plazas: \#últimahora (2M.) y \#COVID19 (1,57M.). Le siguen en el ranking \#CoronavirusEspaña (1,56M.), \#Urgente (673K.), \#YoMeQuedoenCasa (596K.) y \#Covid_19 (476K.). Completan el TOP10 \#Pandemia (465K.) y la etiqueta homenaje a los sanitarios \#AplausoSanitario que congregó más de $432 \mathrm{~K}$. de interacciones.

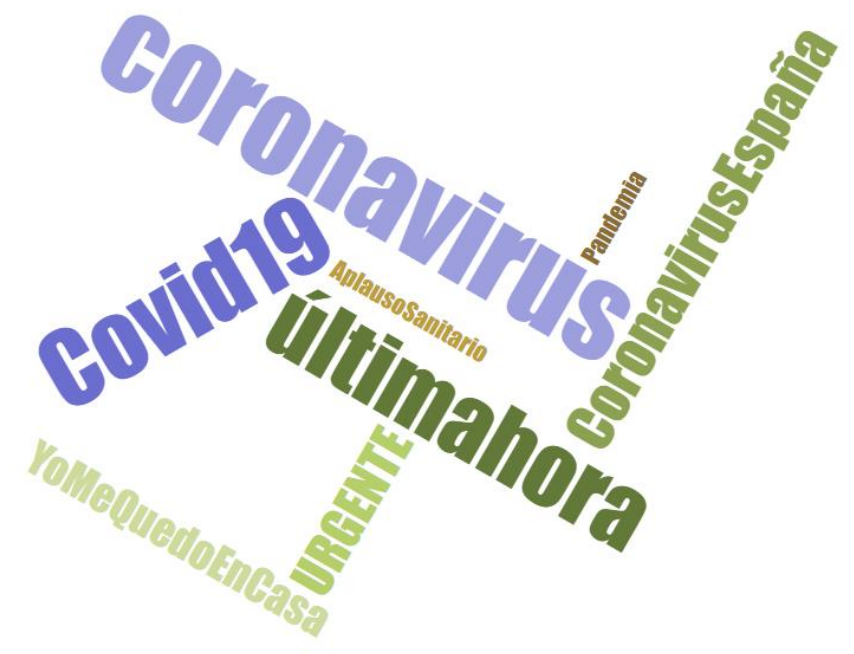

Figura 4. Nube de palabras según los hashtags más empleados

Fuente: Elaboración propia

En cuanto al contenido más demandando y con mejor tasa de interacciones en Facebook por parte de los usuarios, volvemos a refrendar, en este caso, la tesis de que los medios de prensa son los que más seguidores congregan en sus noticias. El post de Facebook con mayor tasa de interacción lo tiene El Mundo (470K), seguido de El País (139K) y ABC (98.9K). Como dato curioso y que, sin duda, invita a la reflexión es la temática de los tres posts que son relativos a temas del COVID-19 de carácter internacional. 
Arrufat Martín, S.

Los medios de comunicación españoles en tiempos de pandemia: generación de noticias en redes sociales durante la COVID-19
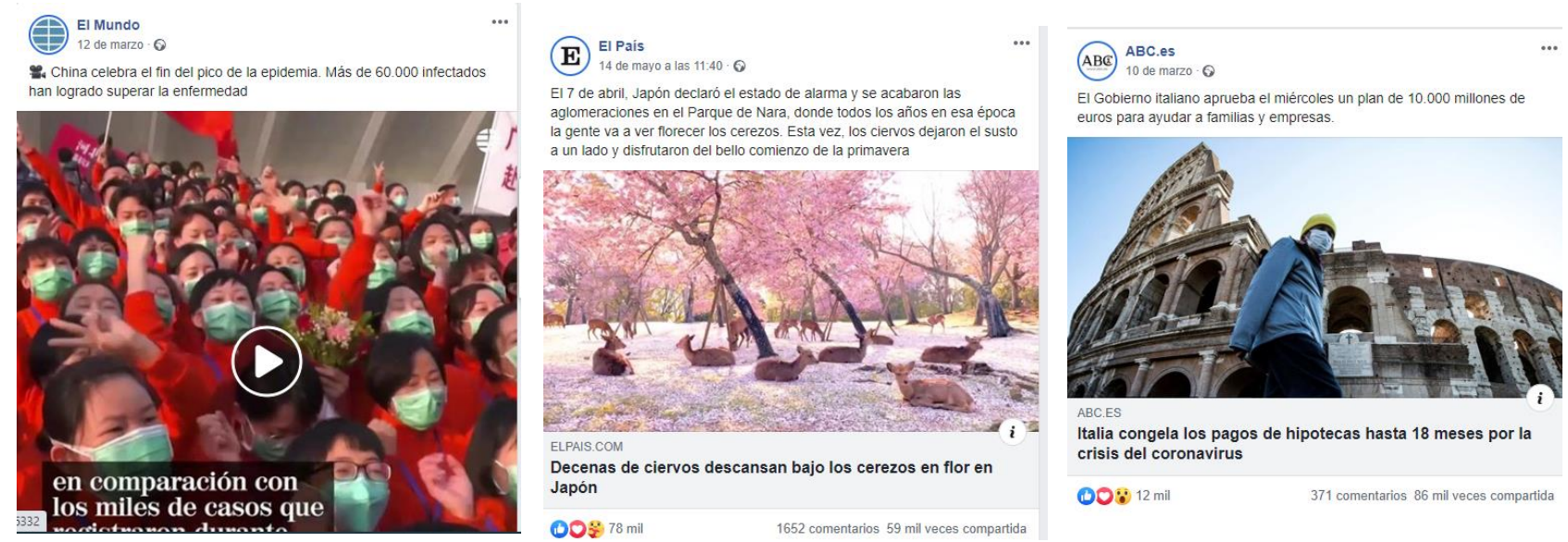

Figura 5. Publicaciones con mayor interacción en Facebook Fuente: Elaboración propia a partir de Facebook

Al igual que en Facebook, el sector de los medios de prensa congrega la mayor tasa de interacción en Twitter. El perfil de $A B C$ en Twitter acaparó la mayor tasa de interacción con la publicación de Ernesto Sevilla (57,3K.), seguido de El Mundo (56,3K. y 52,3K.). De nuevo, observamos como un contenido con temática internacional se cuela entre los primeros, coincidiendo este en contenido y medio con Facebook.
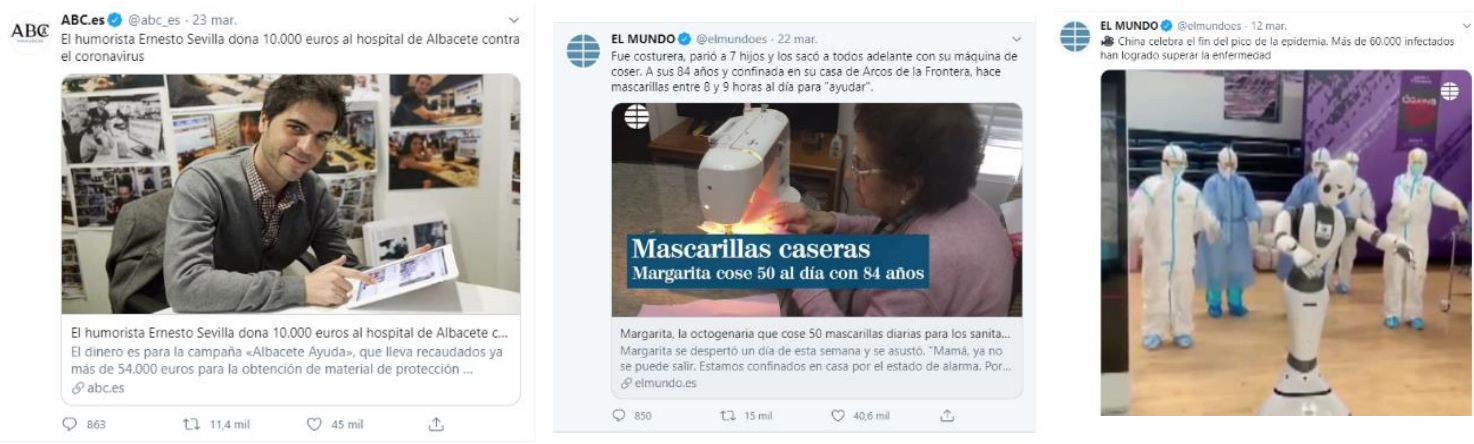

Figura 6. Publicaciones con mayor interacción en Twitter Fuente: Elaboración propia a partir de Twitter

En Instagram, El Mundo logra posicionar a tres publicaciones como las que mayor tasa de interacción congrega. En este sentido, este medio es el líder de todos los analizados en esta red social, acaparando en estas tres publicaciones más de 174,1K. de interacciones. Fotos y videos impactantes de carácter social y emocional hacen de estas tres publicaciones un éxito entre los seguidores.

Vivat Academia. Revista de Comunicación. 2021, nº 154, 107-122 
Los medios de comunicación españoles en tiempos de pandemia: generación de noticias en redes sociales durante la COVID-19
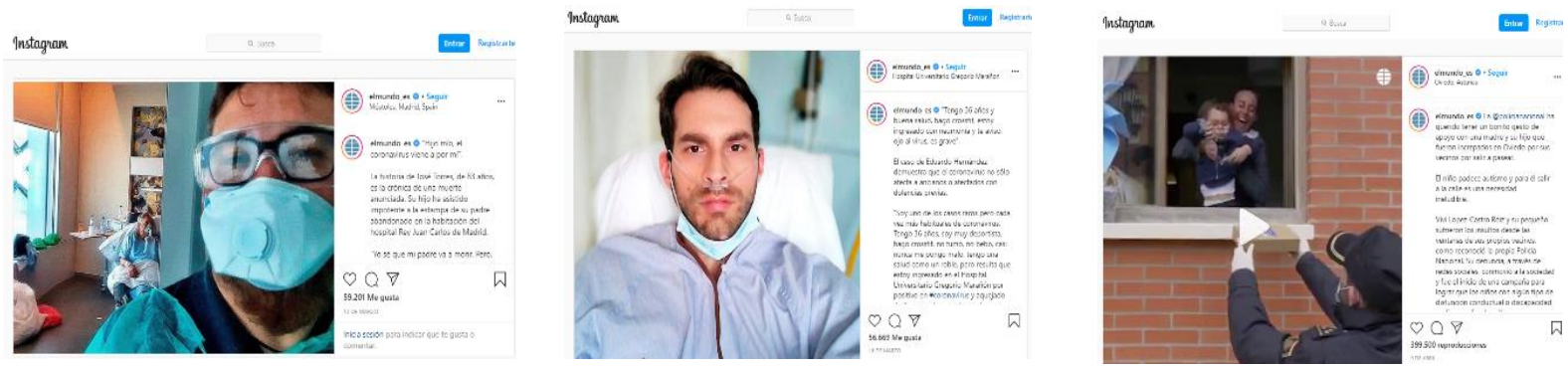

Figura 7. Publicaciones con mayor interacción en Instagram

Fuente: Elaboración propia a partir de Instagram

Por último y en el caso de YouTube, El Mundo vuelve a liderar con su entrevista a Iker Jiménez atrayendo más de $60,8 \mathrm{~K}$ de interacciones y con otra entrevista que se sitúa en tercera posición $(32,1 \mathrm{~K}$.). Asimismo, el video sobre el avance de la vacuna española de El País congrega a más de 41,6K., situándose en segunda posición.
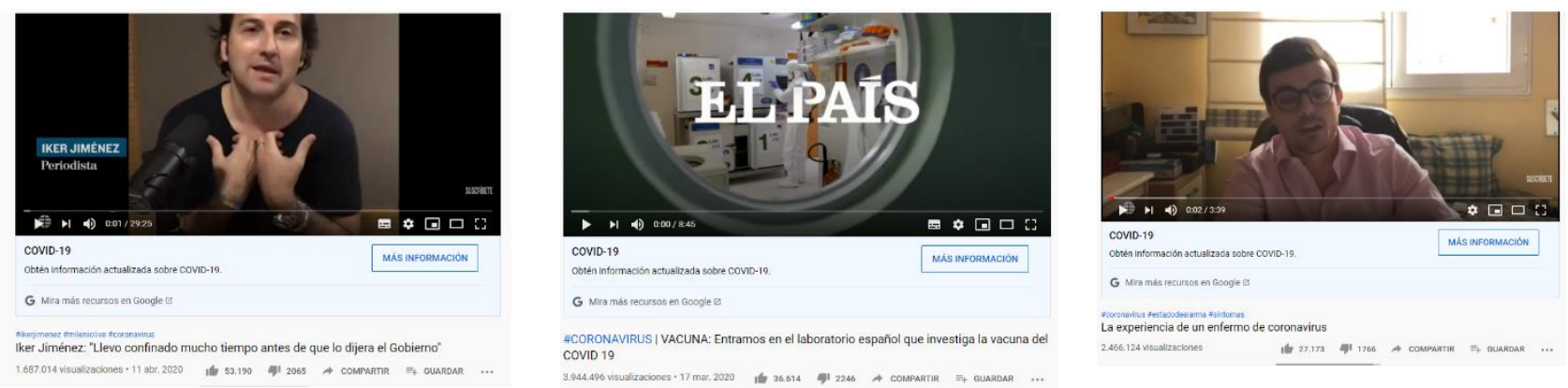

Figura 8. Publicaciones con mayor interacción en YouTube Fuente: Elaboración propia a partir de YouTube

\section{3. ¿Se habla solo del virus durante el confinamiento?}

La gráfica de evolución de publicaciones evidencia como antes del 13 de marzo las publicaciones de los medios de comunicación en redes sociales guardaban una escasa relación con la COVID-19, siendo el 13 de marzo el día que se dispara la atención con respecto a este tema, coincidiendo con el anuncio de declaración del estado de alarma.

Del mismo modo, observamos como durante este mismo mes, el tema central sigue siendo la COVID-19, viéndose esta tendencia ligeramente alterada tras la semana santa y más pronunciada durante el mes de mayo. Si nos fijamos en el número total de publicaciones puede llevarnos a engaño ya que viene a recoger la tendencia de que los medios de comunicación dieron cabida a temas no COVID-19 de una manera más regular después del período estival mencionado, sumando muchas publicaciones durante el mes de mayo y recuperando las bajas cifras que este dato tuvo con respecto al mes de marzo. 


\subsection{2}

TOTAL DE PUBLICACIONES

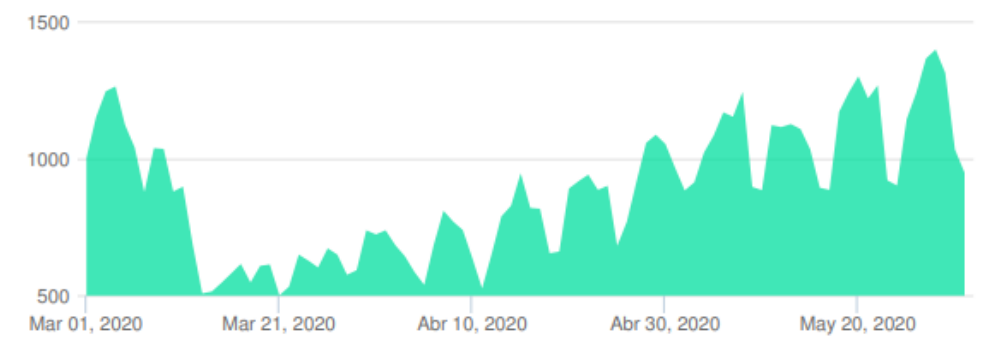

Figura 9. Publicaciones con temática no COVID-19

Fuente: Elaboración propia a partir de Welovroi

Durante los tres meses del estudio, observamos como los temas no COVID-19 que los medios de comunicación emplean en sus redes sociales los encontramos en el sector de la televisión y, concretamente, en Telecinco (\#Supervivientes2020), Antena Tres (\#ElHormiguero) y TVE (\#OT2020).

En cuanto a publicaciones concretas por redes sociales y con mayor tasa de interacciones encontramos en Facebook publicaciones relacionadas con la muerte de Luis Eduardo Aute, prohibición de Sudán de la ablación, renuncia del Rey Felipe VI a la herencia de su padre y la muerte de Julio Anguita. En Twitter, los temas con mayor aceptación fueron el descanso de los ciervos en Japón, $75^{\circ}$ aniversario de la liberación del fascismo en Italia y otros temas políticos a nivel internacional. Por su parte, en la red social Instagram, las publicaciones con mayor tasa de interacciones fueron aquellas relacionadas con el fallecimiento de Álex Lequio, la enfermedad de Dani Rovira y temas de carácter social y televisivos. En YouTube, encontramos en las primeras posiciones videos de Alberto Chicote y videos de Carlos Herrera.

\section{CONCLUSIONES}

Durante los últimos meses, el mundo se ha enfrentado a una pandemia sin antecedentes en más de un siglo que ha sido desbastadora a nivel sanitario, social y económico. La adaptación constante por parte de los medios de comunicación al nuevo contexto mediático dominado por la irrupción de las redes sociales ha supuesto la convergencia de los medios a un sistema híbrido de información dominado por la comunicación tradicional e internet. Los medios comienzan a tener una presencia activa en redes sociales y en el contexto de internet con el firme propósito de ganar notoriedad y buscar una viralización que incremente la difusión de sus contenidos.

La investigación evidencia como el sector de la prensa sigue teniendo mayor aceptación por parte del púbico a la hora de informarse. En este sentido, el diario El País también es el líder indiscutible en cuanto a nivel de interacción se refiere. Asimismo, el estudio también evidencia el cómo los medios de comunicación emplean sus canales de 
Arrufat Martín, S.

Los medios de comunicación españoles en tiempos de pandemia: generación de noticias en redes sociales durante la COVID-19

redes sociales, unos en mayor medida que los otros, para inundar sus perfiles con diferentes noticias de diferente magnitud $y$ alcance. La tendencia a la "sobreinformación" es una de las cuestiones a destacar en este artículo ya que los resultados concluyen que no existe una relación directa entre la tasa de publicación e interacción. En el ámbito televisivo Telecinco es el medio que mayor nivel de interacción logra, seguido de la Cadena Ser en el sector radiofónico.

En cuanto a las redes sociales, Twitter $(48,9 \%)$ ha sido la red que mayor tasa de publicación ha obtenido, seguido por Facebook (45,1\%), Instagram $(4,7 \%)$ y YouTube $(1,4 \%)$. En cambio, la red social que ha tenido una mayor tasa de interacciones ha sido Facebook (70,2\%), seguido de Twitter (13,9\%), Instagram (11,6\%) y YouTube $(4,3 \%)$. Estos resultados vienen a refrendar la tesis de la inexistencia de la relación directa entre publicaciones e interacciones.

Las publicaciones con un alto componente emocional han tenido mayor aceptación que las de carácter racional. En este sentido, Patino (2020: 121) sentencia que cuando se habla de algo importante para el usuario; la dinámica de grupo acentúa mucho más en respuestas emocionales que racionales. En la red social Facebook, encontramos las publicaciones con mayor carga de aceptación en asuntos de información internacional. Twitter, ha sido la red social con mayor tasa de publicación fruto de su carácter instantáneo y con temáticas de lo más variado. Por su parte, en Instagram encontramos publicaciones con un alto componente emocional y social, seguido de YouTube con informaciones de carácter audiovisual y extensas con un alto componente de divulgación científica y carácter investigador.

Los temas de conversación varían en las diferentes etapas. \#coronavirus ha sido la etiqueta más empleada durante los tres meses. También observamos temas sociales como \#YoMeQuedoEnCasa y \#AplausoSanitario. Durante la crisis sanitaria, los medios también han obtenido una elevada difusión en las redes con otras cuestiones; en el caso de las televisiones resulta reveladora la influencia y protagonismo de los programas de entretenimiento. Los medios, de manera generalizada, incluyeron en su agenda y alcanzaron un destacado seguimiento de las noticias relacionadas con la muerte del artista Luis Eduardo Aute y el político Julio Anguita; la renuncia del Rey Felipe VI a la herencia de su padre; y en el ámbito internacional, la prohibición por ley de la mutilación genital femenina en Sudán. Incidiendo en el aspecto social de Instagram, con fines ilustrativos cabe destacar el protagonismo cobrado por el fallecimiento de Alex Lequio, siendo el tema no relacionado con la COVID 19 con mayor difusión. Es a partir del periodo vacacional de semana santa cuando los medios de comunicación varían su dinámica y flujos de información para difundir noticias ya no tan centradas en la pandemia, sino también en otros aspectos sociales, culturales, deportivos y económicos.

Este estudio también evidencia los cambios por parte de los ciudadanos en el consumo de información durante el Estado de Alarma como ya se reflejan en otros estudios y en situaciones de crisis similares (Seeger; Sellnow; Ulmer, 2003). Los ciudadanos, en situaciones de crisis, tienen la necesidad de conocer y obtener la mayor cantidad de información posible. Sin embargo, en ocasiones, la necesidad de estar

Vivat Academia. Revista de Comunicación. 2021, nº 154, 107-122 
Arrufat Martín, S.

Los medios de comunicación españoles en tiempos de pandemia: generación de noticias en redes sociales durante la COVID-19

informado debido a la excepcionalidad de la situación, puede crear un sentimiento de sobreexposición o sobreinformación en la persona, creando "una cierta fatiga por la sobreabundancia de noticias sobre el tema (Masip et ál., 2020:9). Esta situación junto con la proliferación de las redes sociales como fuente de información produce, en palabras de Thompson et al., (2017), una mayor angustia a mayor exposición informativa, siendo variables necesarias para el análisis con el objetivo de que puedan determinar nuevos modelos o teorías sobre el comportamiento en redes sociales.

\section{REFERENCIAS}

Abraham, T. (2005). Twenty-first century plague: The story of SARS. Johns Hopkins University Press.

Aleixandre-Benavent, R., Castelló-Cogollos, L. y Valderrama-Zurián, J. (2020). Información y comunicación durante los primeros meses de Covid-19. Infodemia, desinformación y papel de los profesionales de la información. Profesional de la información, 29(4), e290408. https:// doi.org/10.3145/epi.2020.jul.08

Andreu-Sánchez, C. y Martín-Pascual, M. A. (2020). Fake images of the SARS-CoV-2 coronavirus in the communication of information at the beginning of the first Covid19 pandemic. El profesional de la información, 29(3), e290309. https://doi.org/10.3145/epi.2020.may.09

Baraybar-Fernández, A., Arrufat-Martín, S. y Rubira-García, R. (2020). Religion and Social Media: Communication Strategies by the Spanish Episcopal Conference. Religiones, 11, 239. https://doi.org/10.3390/rel11050239

Casero-Ripollés, A. (2020). Impact of Covid-19 on the media system. Communicative and democratic consequences of news consumption during the outbreak. El profesional de la información, 29(2). https:/ / doi.org/10.3145/epi.2020.mar.23

Ceron, A., Curini, L., Iacus, S. M. y Porro, Gi. (2014). Every tweet counts? How sentiment analysis of social media can improve our knowledge of citizens' political preferences with an application to Italy and France. New media and society, 16(2), 340358. https:// doi.org/10.1177/1461444813480466

Chadwick, A. (2013). The hybrid media system: Politics and power. University Press.

Costa-Sánchez, C., Rodríguez-Vázquez, A. I., López-García, X. (2015). Del periodismo transmedia al replicante. Cobertura informativa del contagio de ébola en España por Elpais.com. El profesional de la información, 24(3), 282-290. http://dx.doi.org/10.3145/epi.2015.may.08 
Arrufat Martín, S.

Los medios de comunicación españoles en tiempos de pandemia: generación de noticias en redes sociales durante la COVID-19

España (2020). Real decreto 463/2020, de 24 de marzo, por el que se declara el estado de alarma para la gestión de la situación de crisis sanitaria ocasionada por el Covid19. BOE, n. 67. https://www.boe.es/buscar/act.php?id=BOE-A-2020-3692

Guallar, J., Suau, J., Ruiz-Caballero, C., Sáez, A. y Masip, P. (2016). Redistribución de noticias y debate público en las redes sociales. El profesional de la información, 25(3), 358-366. http://dx.doi.org/10.3145/epi.2016.may.05

International Advertising Bureau Spain (2020). Estudio Redes Sociales 2020. https:/ / iabspain.es/estudio/?_sft_publicacion=2020\&amp;_sft_tipo_documento= estudio\&amp;_sft_post_pais=espana

Larson, H. J. (2020). Blocking information on Covid-19 can fuel the spread of misinformation. Nature, 580(7803), 306. https://doi.org/10.1038/d41586-020$\underline{00920-\mathrm{W}}$

Lázaro-Rodríguez, P. y Herrera-Viedma, E. (2020). Noticias sobre Covid-19 y 2019-nCoV en medios de comunicación de España: el papel de los medios digitales en tiempos de confinamiento. El profesional de la información, 29(3). https://doi.org/10.3145/epi.2020.may.02

Lubens, P. (2015). Journalists and public health professionals: Challenges of a symbiotic relationship. Disaster medicine and public health preparedness, 9(1), 5963. https://doi.org/10.1017/dmp.2014.127

Masip, P., Aran-Ramspott, S., Ruiz-Caballero, C., Suau, J., Almenar, E., \& PuertasGraell, D. (2020). Consumo informativo y cobertura mediática durante el confinamiento por el Covid-19: Sobreinformación, sesgo ideológico y sensacionalismo. El Profesional de la Información, 29(3). https:// doi.org/10.3145/epi.2020.may.12

Newman, N., Fletcher, R., Kalogeropoulos, A. y Nielsen, R. K. (2019). Reuters Institute digital news report 2019. Oxford: Reuters Institute for the Study of Journalism. https://reutersinstitute.politics.ox.ac.uk/sites/default/files/201906/DNR_2019_FINAL_0.pdf

Patino, B. (2020). La civilización de la memoria de pez. Alianza Editorial.

Renn, O. (1991). Risk communication and the social amplification of risk. En R. E. Kasperson \& P. J. M. Stallen (Eds.), Communicating Risks to the Public (pp. 287-324). Springer Netherlands. https://doi.org/10.1007/978-94-009-1952-5_14

Seeger, M. W., Sellnow, T. L., \& Ulmer, R. R. (1998). Communication, Organization, and Crisis. Annals of the International Communication Association, 21(1), 231276. https://doi.org/10.1080/23808985.1998.11678952 
Arrufat Martín, S.

Los medios de comunicación españoles en tiempos de pandemia: generación de noticias en redes sociales durante la COVID-19

Slovic, P. (1987). Perception of risk. Science, 236(4799), 280-285. https://doi.org/10.1126/science.3563507

Thompson, R. R., Garfin, D. R., Holman, E. A., \& Silver, R. C. (2017). Distress, Worry, and Functioning Following a Global Health Crisis: A National Study of Americans' Responses to Ebola. Clinical Psychological Science, 5(3), 513521. https://doi.org/10.1177/2167702617692030

Papacharissi Zizi, A. (2010). A Private Sphere. Democracy in a Digital Age. Polity Press.

Wolf, M. (2001). Los efectos sociales de los media. Paidós.

Yu, Y., Duan, W. y Cao, Q. (2013). The impact of social and conventional media on firm equity value: A sentiment analysis approach. Decision support systems, 55(4), 919926. https://doi.org/10.1016/j.dss.2012.12.028

\section{AUTOR}

\section{Sandro Arrufat Martín}

Profesor Asociado en la Universidad Rey Juan Carlos y docente e investigador en EAE Business School. Doctor en Ciencias de la Comunicación por la Universidad Rey Juan Carlos. Asimismo, ha participado en varias investigaciones relacionadas con la gestión y estrategias de la comunicación digital, redes sociales y reputación corporativa. Del mismo modo, tiene entre sus líneas de investigación las relaciones públicas, marca y comunicación corporativa. Actualmente, director de Comunicación y Relaciones Institucionales en Santander Financial Institute (SANFI), centro de la Fundación UCEIF cuyos patronos son Banco Santander y Universidad de Cantabria. Graduado en Periodismo (2016), Máster en Dirección de Comunicación Corporativa por EAE Business School (2017) y Máster en Protocolo, Comunicación y Organización Integral de Eventos por la Universidad Rey Juan Carlos (2018).

sandro.arrufat@urjc.es

Orcid ID: $\underline{\text { https:/ / orcid.org/0000-0002-3104-4765 }}$ 